This is the author's final, peer-reviewed manuscript as accepted for publication. The publisher-formatted version may be available through the publisher's web site or your institution's library.

\title{
Biodegradation of carbon tetrachloride in simulated groundwater flow channels
}

S. Santharam, L. C. Davis, L. E. Erickson

\section{How to cite this manuscript}

If you make reference to this version of the manuscript, use the following information:

Santharam, S., Davis, L. C., \& Erickson, L. E. (2014). Biodegradation of carbon tetrachloride in simulated groundwater flow channels. Retrieved from http://krex.ksu.edu

\section{Published Version Information}

Citation: Santharam, S., Davis, L. C., \& Erickson, L. E. (2014). Biodegradation of carbon tetrachloride in simulated groundwater flow channels. Environmental Progress \& Sustainable Energy, 33(2), 444-453.

Copyright: ( $) 2013$ American Institute of Chemical Engineers

Digital Object Identifier (DOI): doi:10.1002/ep.11808

Publisher's Link: http://onlinelibrary.wiley.com/doi/10.1002/ep.11808/full

This item was retrieved from the K-State Research Exchange (K-REx), the institutional repository of Kansas State University. K-REx is available at http://krex.ksu.edu 


\title{
Biodegradation of Carbon Tetrachloride in Simulated Groundwater
}

\section{Flow Channels}

S. Santharam, corresponding author, is currently Senior Corporate Engineer at Bob J Johnson \& Associates, Inc, Houston, TX; 281-873-5555 Ext 136; ssantharam@bjja.com

L.C. Davis is a Professor, Department of Biochemistry and Molecular Biophysics, Chalmers Hall, Kansas State University, Manhattan, KS; (785)532-6124; 1davis@ksu.edu.

L.E. Erickson is a Professor, Department of Chemical Engineering, Durland Hall, Kansas State University, Manhattan, KS; (785)532-4313; lerick@ksu.edu.

\begin{abstract}
Remediation feasibility studies were conducted in simulated groundwater flow channels for carbon tetrachloride (CT). CT was introduced at a concentration of about $2 \mathrm{mg} / \mathrm{L}(\sim 13$ $\mu$ moles/L) in three channels, two of them with alfalfa plants and the other with grass. Since no degradation products were found at the outlet after about 100 days, anaerobic conditions were created by adding one liter of $0.2 \%$ glucose solution in one channel (with alfalfa) and one liter of $0.1 \%$ emulsified soy oil methyl esters (SOME) to another channel (with alfalfa). The fraction removals of total chlorinated methanes in the outlet liquid were $94 \%$ in glucose fed channel and 92\% in SOME fed channel. Supplements such as glucose, corn starch, cheese whey and SOME stimulated the indigenous microbes to carry out the biodegradation of CT. In both glucose and SOME fed channels, the degradation continued several weeks after stopping the feeding of supplements. Most of the degradation process took place in the initial portion of the SOME fed channel, since SOME likely stayed near the inlet of the channel, due to sorption and retarded
\end{abstract}


flow due to its low solubility; therefore, SOME should be added at multiple locations for effective bioremediation. No CT and degradation products were found in the headspace above the soil surface.

Keywords: Carbon Tetrachloride, Groundwater, Bioremediation, Soy Oil Methyl Esters, Glucose, Cheese Whey. 


\section{Introduction}

Carbon tetrachloride (CT) is a solvent used in the past in several applications: as a refrigeration fluid and propellant for aerosol cans; as a cleaning fluid, a degreasing agent, and a spot remover; in fire extinguishers and as a pesticide fumigant. Because of its harmful effects, most of these uses were banned in the 1960s; its use as a pesticide was banned in 1986. Today CT is only used in some industrial applications [1]. Although many uses have been discontinued, the possibility still exists for CT to be released to the environment, primarily from industrial processes or old containers of household cleaning agents. CT is widely dispersed and persistent in the environment, but is seldom detected in foods [1]. The degradation of CT occurs both in biologically active systems [2-4], and in abiotic systems [5-7].

Degradation of CT occurs slowly in the environment, which contributes to the wide spread occurrence of the chemical in groundwater [1]. Although indigenous microorganisms may degrade $\mathrm{CT}$, a common degradation product, chloroform (CF), may be more persistent than CT [8]. CF is readily formed under anaerobic conditions [9]. The degradation products of $\mathrm{CT}$, by reductive dechlorination, in addition to $\mathrm{CF}\left[\mathrm{CHCl}_{3}\right]$, are methylene chloride ( $\mathrm{MC}$ $\left.\left[\mathrm{CH}_{2} \mathrm{Cl}_{2}\right]\right)$, chloromethane $\left(\mathrm{CM}\left[\mathrm{CH}_{3} \mathrm{Cl}\right]\right)$, and methane $\left[\mathrm{CH}_{4}\right]$. The dehalogenation reaction pathway is as shown below:

$$
\begin{aligned}
& \mathrm{CCl}_{4}+\mathrm{H}_{2} \rightarrow \mathrm{CHCl}_{3}+\mathrm{HCl} \\
& \mathrm{CHCl}_{3}+\mathrm{H}_{2} \rightarrow \mathrm{CH}_{2} \mathrm{Cl}_{2}+\mathrm{HCl} \\
& \mathrm{CH}_{2} \mathrm{Cl}_{2}+\mathrm{H}_{2} \rightarrow \mathrm{CH}_{3} \mathrm{Cl}+\mathrm{HCl} \\
& \mathrm{CH}_{3} \mathrm{Cl}+\mathrm{H}_{2} \rightarrow \mathrm{CH}_{4}+\mathrm{HCl}
\end{aligned}
$$


For reductive dechlorination of $\mathrm{CT}$ to occur, anaerobic conditions must prevail; to deplete the oxygen present in the groundwater, organic substrates have to be supplied. For reductive dechlorination, electrons and hydrogen ions are necessary to replace the chlorine atoms. These requirements are met by organic compounds such as glucose, acetate, lactate, cheese whey, molasses, or vegetable oils. Subsequent migration of the transformation products to an aerobic environment can lead to oxidation of the products with ultimate complete mineralization of the halogenated aliphatic compounds to chloride ion and carbon dioxide [9]. McQuillan et al. [10] ascribed intrinsic remediation of $\mathrm{CT}$ to spilled gasoline, and Witt et al. [11] demonstrated that supplementing with acetate enhanced the removal of CT by indigenous bacterial populations, but better results were obtained when specific inoculant was added. Gregory et al [12] successfully used $\mathrm{Fe}(0)$ and enrichment with methanogenic organisms to dehalogenate $\mathrm{CT}$ in laboratory experiments. However, one of the problems encountered in early biostimulation studies was intermediate product accumulation; for instance, chloroform accumulated to levels up to $30-60 \%$ of the initial CT concentration [8]. Research studies to date have used several electron donors including acetic acid [13-16], methanol [17]; lactate, emulsified vegetable oil, and corn syrup [18]; menaquinones [19]; fulvic acids [20]; and, humic acids [21]. However, SOME and cheese whey have not been evaluated by other researchers. In this study, we have evaluated the effectiveness of inexpensive substrates such as SOME and cheese whey.

Research on CT biodegradation in simulated groundwater flow conditions is lacking. Although batch studies provide useful results, they do not reflect the actual conditions in the field. In this work, the degradation of $\mathrm{CT}$ was studied in a groundwater simulated soil channel system. This is important when SOME is used because of its unpredictable fate under flow conditions. 


\section{Materials and Methods}

\section{Experimental System or Mesocosm}

A steel chamber was divided into six channels; each channel was $110 \mathrm{~cm}$ long, $65 \mathrm{~cm}$ high and $10 \mathrm{~cm}$ wide. Channels 1-3 were used for a different study and channels 4, 5 and 6 were used for the CT bioremediation study described in this work. The channels were filled with alluvial silty sand ( $<10 \%$ silt) up to $\sim 60 \mathrm{~cm}$. The soil was collected from a site near a landfill in Riley County, Kansas in 1993 [22-24]. Alfalfa was grown on channels 5 and 6, while fescue grass was grown on channel 4. A pair of fluorescent tube lights $(40 \mathrm{~W})$ for each channel, placed at a height of $50 \mathrm{~cm}$ above the soil surface, provided the light source for the plants. The photosynthetically active radiation (PAR) at $40 \mathrm{~cm}$ from the soil surface (the average plant height) was about $160 \mu \mathrm{E} / \mathrm{m}^{2} / \mathrm{s}$ (measured by using a L1-188B Integrating Quantum Radiometer/Photometer) [22].

The inlet solution was fed at $5 \mathrm{~cm}$ above the bottom of the channels (Figure 1).Approximately $2 \mathrm{mg} / \mathrm{L}(\sim 13 \mu$ moles/L) CT solution was introduced starting from March 12 , 2004 (day 0). The concentration at which CT was introduced was well above the maximum contaminant level (MCL) of CT in drinking water: $0.005 \mathrm{mg} / \mathrm{L}$. The height of saturated zone in each channel was controlled by the position of the end of each outlet tube $(25 \mathrm{~cm}$ in this system). Plants were harvested at the beginning of each month by cutting the top portion; after harvest, the plant height was approximately $10 \mathrm{~cm}$. At the end of each month, the fescue grass and alfalfa grew to a height of approximately $50 \mathrm{~cm}$ and $70 \mathrm{~cm}$, respectively. After the initial preparation of inlet CT solution, $100 \mathrm{~mL}$ of CT stock solution $(\sim 40 \mathrm{mg} / \mathrm{L}$ of CT) and $900 \mathrm{~mL}$ of distilled water were added every day to the inlet bottles. 
In channel 6, there were five monitoring wells made of sintered alumina connected to polyethylene tubes through which groundwater samples could be collected from near the bottom of the channel (Figure 1). The wells were placed at a distance of $17 \mathrm{~cm}, 35 \mathrm{~cm}, 60 \mathrm{~cm}, 73 \mathrm{~cm}$ and $100 \mathrm{~cm}$ from the inlet. The depth of the wells was $60 \mathrm{~cm}$ and the bottom of each well was about $0.2 \mathrm{~cm}$ from the bottom of the channel. Wells were not installed in channels 4 and 5 .

\section{Inlet/Outlet Analysis}

After introducing the $\mathrm{CT}$ solution, the concentrations of the $\mathrm{CT}$ and degradation products at the inlet and the outlet of the channels were monitored. A $10 \mathrm{~mL}$ sample was collected from the inlet tube at the entrance to each channel and a $10 \mathrm{~mL}$ sample was collected from the outlet at the discharge end. Samples were collected using a $10 \mathrm{~mL}$ syringe and transferred to a $25 \mathrm{~mL}$ vial and closed with a mininert cap immediately. The compounds in the sample were allowed to partition into the headspace and attain equilibrium by slight shaking of the vial. The headspace samples were analysed with a gas chromatograph (GC) as described below.

\section{Biostimulation by Glucose, Corn Starch, Cheese Whey and Soy Oil Methyl Esters}

Since no degradation was observed after 100 days, carbon sources were added to stimulate growth of indigenous microbes, to create anaerobic conditions, and also for supplying hydrogen and electrons required for reductive dechlorination. Introduction of one liter of $0.2 \%$ glucose solution (Dextrose, anhydrous; Fisher Chemicals, Fairlawn, NJ) as an electron donor into channel 5 resulted in anaerobic conditions in the channel. The glucose solution was fed once every month starting from day 110 and continued until day 236 and once on day 837. Corn starch was fed, inadvertently, instead of glucose on days 266, 299 and 328. From day 903 until day 
1136, twenty doses of cheese whey solution ( $1 \mathrm{~mL}$ in $1 \mathrm{~L}$ distilled water) were added to channel 5 through the inlet (Table ).

From day 203, one liter of $0.1 \%$ emulsified soy oil methyl esters (SOME) was fed to channel 6. As SOME is hydrophobic and barely soluble in water, it tends to stay near the inlet of the channel when injected at the inlet. To enhance biostimulation in the later part of the channel, occasionally SOME was injected directly into the soil system through a monitoring well instead of the inlet. The glucose, corn startch and cheese whey addition dates in channel 5 and SOME addition dates and locations in channel 6 are listed in Table 1. The supplement solution was fed at the inlet, unless mentioned otherwise.

\section{Soil Sample Analysis}

After 96 days of exposure to CT solution, soil samples were collected, at a distance of 30 $\mathrm{cm}$ from the inlet, at four different depths from the soil surface: $0-8 \mathrm{~cm}, 12-20 \mathrm{~cm}, 22-30 \mathrm{~cm}$ and $34-42 \mathrm{~cm}$, from all three channels. The samples were collected with a soil core and iron rods of different lengths to collect samples at different depths. Soil sample collected at each depth was transferred to a $25 \mathrm{~mL}$ vial and immediately closed with a mininert cap; the vial was shaken gently and the headspace was analysed with GC. The sample headspace was analysed for CT and degradation compounds and the concentration in the aqueous phase of the soil was estimated using a calibration curve and by performing a mass balance [23-24] before and after partitioning of compounds into the headspace of the vial.

The soil sample with the vial was dried in a vacuum oven (Thelco vacuum oven, Precision Scientific Co., Chicago, IL) at $80^{\circ} \mathrm{C}$ for 24 hours and the dry weight of soil was determined. The difference between the mass of vial with moist soil and dry soil yields the mass 
of water present in the soil sample. The difference between the mass of vial with dry soil and the tare mass of vial yields the mass of dry soil.

A sorption study was also conducted to estimate the fraction of organic carbon content $\left(f_{o c}\right)$ in the soil samples collected on day 151. After analyzing for the chlorinated methanes' concentrations, the soil samples were spiked with $1 \mathrm{~mL}$ of perchloroethene (PCE)-CT standard mixture. The standard was prepared by injecting $10 \mu \mathrm{L}$ of PCE liquid and $10 \mu \mathrm{L}$ of CT liquid in a clean amber glass bottle of volume 4.2 liters. The concentrations of PCE and CT in the standard bottle are, therefore, $3.83 \mathrm{mg} / \mathrm{L}$ and $3.76 \mathrm{mg} / \mathrm{L}$. One $\mathrm{mL}$ of this gas mixture is then spiked onto the soil samples and a control. The control was prepared with 5 gms of glass beads (3 mm diameter, Arthur H. Thomas Co., Philadelphia, PA) and $1 \mathrm{~mL}$ of distilled water. The headspace concentrations were analysed and the organic carbon fraction $\left(f_{o c}\right)$ is then estimated by mass balance [23-24].

\section{Gas Phase Analysis}

Gas phase samples at the soil surface were obtained by placing $400 \mathrm{~mL}$ metal containers with the open end down on the surface of the soil. After 4 hours, $0.5 \mathrm{~mL}$ of the gas in the container was drawn through a septum and analyzed in the gas chromatograph [24].

\section{Tracer Study}

A tracer study was conducted, using potassium bromide $(\mathrm{KBr})$, to determine the residence time of the liquid entering at the inlet. In addition to recording the time at which the tracer exits the channel, the corresponding volume of outlet liquid was also measured because it varies with the plant size, which in turn varies with the time of the month. The outlet liquid volume is a better parameter for estimating the tracer response because the time for peak of 
bromide concentration depends on the growth stage of the plants. In the tracer study, $150 \mathrm{~mL}$ of $\mathrm{KBr}$ solution, at a concentration of $100 \mathrm{mg} / \mathrm{L}(10.05 \mathrm{mg}$ as bromide), was injected at the inlet of each channel through separating funnels, on June 4, 2004 (day 0 of tracer study). Since the plants were harvested on June 1,2004, the evapotranspiration was relatively low and consequently the volume of outlet liquid was relatively high. On first and second day, samples were collected from the outlet at intervals of $3 \mathrm{hrs}, 6 \mathrm{hrs}, 12 \mathrm{hrs}$ and $24 \mathrm{hrs}$. On third and fourth day, two samples, at $5 \mathrm{hrs}$ and $24 \mathrm{hrs,}$, were collected. From fifth day onwards, a sample was collected every day, up to 14 days, and analysed for bromide concentration. The mean residence time for the bromide in each channel was estimated from the expression [25],

$$
\tau=\frac{\sum t_{i} C_{i} \Delta t_{i}}{\sum C_{i} \Delta t_{i}}
$$

where

$$
\begin{aligned}
& \tau=\text { mean residence time, days } \\
& C_{i}=\text { concentration of bromide in the } i^{\text {th }} \text { sample, mg/L } \\
& t_{i}=\text { time at which the } i^{\text {th }} \text { sample was collected, day } \\
& \Delta t_{i}=\text { Difference between }(i+1)^{\text {th }} \text { sampling time and } i^{\text {th }} \text { sampling time, days }
\end{aligned}
$$

A portion of the bromide will be transported upward through the soil column due to evapotranspiration by plants. This portion of bromide gets trapped in the soil column above the primary flow path. The mass of bromide trapped in the soil is estimated based on the daily water uptake of plants and the concentration of the bromide in the outlet for that day. The composite concentration of the bromide entering the vadose zone in the water taken up is assumed to be the same as the composite concentration of bromide in the outlet liquid. When two or more samples were collected during the initial period of study, the average concentration of bromide was used to estimate the mass of bromide transported upward. 


\section{Analytical Methods}

Chlorinated compounds and methane were analysed using a gas chromatograph (HP 5890 Series II, Wilmington, DE) equipped with a Flame Ionization Detector (FID) and a HP-1 column (Dimethyl Polysiloxane matrix, $30 \mathrm{~m}$ x $0.53 \mathrm{~mm}$, Agilent Technologies, Wilmington, DE). Hydrogen was the carrier gas. The injector temperature was set at $200^{\circ} \mathrm{C}$ and the detector temperature was set at $300^{\circ} \mathrm{C}$. Sample volume of $100 \mu \mathrm{L}$ was injected in the column at $100^{\circ} \mathrm{C}$ and run for 5 minutes. For the above conditions and gas flow rate of $1.5 \mathrm{~mL} / \mathrm{min}$, the elution times of CT, CF, MC and methane are approximately $1.4 \mathrm{~min}, 1.1 \mathrm{~min}, 0.85 \mathrm{~min}$ and $0.6 \mathrm{~min}$. The detection limits for $\mathrm{CT}, \mathrm{CF}, \mathrm{MC}$ and methane, in the gas phase, with the above conditions, are $4.3 \mu \mathrm{g} / \mathrm{L}(0.028 \mu \mathrm{M}), 2.7 \mu \mathrm{g} / \mathrm{L}(0.023 \mu \mathrm{M}), 1.5 \mu \mathrm{g} / \mathrm{L}(0.018 \mu \mathrm{M})$ and $0.12 \mu \mathrm{g} / \mathrm{L}(0.0075$ $\mu \mathrm{M})$, respectively.

For the tracer analysis, the outlet liquid collected was transferred to a $1.5 \mathrm{~mL}$ centrifuge tube and centrifuged at 10,000 rpm for 2 minutes. The supernatant was then transferred to a 2 mL clear vial with white septum and threaded black cap (National Scientific Company, Rockwood, TN) for bromide analysis using an ion chromatograph (Dionex DX500 Series, Sunnyvale, CA) equipped with a conductivity detector and analytical column (Ionpac, AS9-HC, $4 \times 250 \mathrm{~mm}$ ). The eluent solvent was $9 \mathrm{mM}$ sodium carbonate at a flow rate of $1 \mathrm{~mL} / \mathrm{min}$. Under these conditions, the approximate elution times were $6.3 \mathrm{~min}$ for chloride, $9.5 \mathrm{~min}$ for bromide, $11 \mathrm{~min}$ for nitrate and and $18 \mathrm{~min}$ for sulfate. The sample volume injected was $25 \mu \mathrm{L}$ and each sample was run for 20 minutes.

\section{Results and Discussion}




\section{Tracer Studies}

The time and the outlet liquid volume at which peak concentration of bromide occurred and the residence time distribution for each channel are shown in Figure 2 and Table 2. The mean residence time (MRT) was estimated from the residence time distribution of tracer in the effluent [25]. The peak of bromide concentration in the outlet of the three channels occurred between 1.1 to 1.5 days corresponding to an outlet liquid volume of $1.1 \mathrm{~L}$ to $1.4 \mathrm{~L}$ with mean residence time ranging from 2.8 to 3.6 days.

The flow rate of the contaminant solution inside the channel varied in a 24-hour period, as the head in the inlet bottle decreases. The maximum flow rate occurred immediately after watering and the minimum flow rate occurred at the end of a 24-hour period. Based on the bromide peak arrival time, the average flow rate was estimated to be approximately $98 \mathrm{~cm} / \mathrm{d}(3.3$ $\mathrm{ft} / \mathrm{d})$ for channel 4; $77.5 \mathrm{~cm} / \mathrm{d}(2.6 \mathrm{ft} / \mathrm{d})$ for channel 5 ; and $88 \mathrm{~cm} / \mathrm{d}(2.9 \mathrm{ft} / \mathrm{d})$ for channel 6 . In addition to the diurnal variation, the flow rate also varies depending on the plant size or the time of the month.

Table 3 presents the cumulative outlet liquid volume, mass of bromide eluted in the outlet, estimated mass of bromide transported to vadose zone by upflow due to evapotranspiration and the total bromide accounted for by these processes and the recovery percentage. Assuming a porosity of 0.3 , the amount of water present in the saturated zone can be estimated to be $8.25 \mathrm{~L}$. However, the bromide elutes corresponding to a liquid volume of about 1.3 $\mathrm{L}$. There is evidence of channeling, therefore, in the saturated zone associated with flow from the inlet to the outlet. The entire amount of bromide $(10.05 \mathrm{mg})$ introduced at the inlet was not recovered at the outlet because a portion of the solution is transported upward due to evapotranspiration and another portion is dispersed in the saturated zone; the recovery ranged 
from $62 \%$ to $74 \%$. Although, the experiment was carried out for only 14 days, bromide may still be eluting at low concentrations at the end of the experiment. In Table 4, the solution recovery is compared to the bromide recovery. In addition to the above factors, the assumptions made in estimating the bromide transported by evapotranspiration can also contribute to the lower recovery of bromide. A lower recovery is expected for the tracer when added as a pulse in a vegetated zone as reported by others [26-27]. In the tracer tests conducted in 12 wetland research cells, Whitmer et al. [26] observed an average bromide recovery of $48 \%$. Although loss of water by infiltration, analytical biases, and inadequate measurement period were potential causes of low bromide recovery, the authors believe the nonconservative behavior of bromide was probably caused by plant uptake. Brandi-Dohrn et al. [27] reported a $67 \%$ recovery of bromide in a tracer test conducted on a field site at the North Willamette Research and Extension Center, Aurora, Oregon. The results observed in this study are comparable to what were reported in previous studies.

The evapotranspiration in each channel varied at different times of a month due to plant harvesting at the beginning of each month. Because of variation in plant size over a month, the outlet liquid volume also varies and, consequently, the mean residence time of the compounds also varies. Table 5 presents the variation for the daily outlet liquid volume, which was recorded every day throughout the duration of the experiment, for channels 4,5 and 6 . The variation of the daily outlet liquid volume from the beginning to the end of one month is $0.9 \mathrm{~L}-0.6 \mathrm{~L}$ for channel 4, 0.9 L - 0.6 L for channel 5, and 0.9 L - 0.4 L for channel 6 .

\section{Inlet/Outlet Concentrations}

Figures 3 through 5 show the inlet CT, outlet CT and degradation compound concentrations for channels 4, 5 and 6 . In channel 4 where no substrate was added, the outlet 
concentrations of the degradation compounds were low, during most of the sampling events, and the concentrations of CT in the inlet and outlet were similar (Figure 3).

\section{Channel 5: Glucose/Corn Starch/Cheese Whey}

Figure 4 shows the CT degradation in the glucose/corn starch/cheese whey treated channel 5. From day 150, forty days after the first addition of glucose, the outlet CT concentration started to decrease gradually and reached a low value (less than $2 \mu \mathrm{M}$ ) by day 230 . Chloroform (CF) was observed, but never exceeded a concentration of $3 \mu \mathrm{M}$. Methylene Chloride (MC) was also detected but mostly remained less than $1 \mu \mathrm{M}$. Even after stopping the feeding of supplement on day 328, CT degradation continued for many weeks. The glucose fed earlier provided sufficient substrate for several months.

As shown in Figure 4, the total chlorinated methanes (CMes) in the outlet dropped to about $2 \mu \mathrm{M}$ by day 246 and remained at a lower concentration through day 475 , after which the values started to increase, most likely due to lack of electron donor and carbon source. After about day 600 , the outlet CT concentration was between 5 and $10 \mu \mathrm{M}$ and the concentration of CF was mostly about $1 \mu \mathrm{M}$. Although the outlet CT concentration started to increase, it did not reach the inlet level, indicating that biodegradation was taking place. Glucose solution added on day 837 resulted in a decrease of outlet CT concentration until day 885 . However, after the depletion of glucose and glucose-derived compounds in the channel, the outlet CT concentration increased again to values close to the inlet $\mathrm{CT}$ concentration. Continuous detection of $\mathrm{CF}$ and outlet CT values less than inlet CT concentration indicated on-going biodegradation in the channel.

The key to the identification of reductive dechlorination pathway is the presence of degradation products. The success of reductive dechlorination is therefore dependent on 
continuing this reduction to completion so that neither contaminant nor its degradation products are above site closure criteria [28]. From the field data or laboratory treatability test data, the site-specific stoichiometry can be defined. This is important to ascertain the concentration of electron donor and nutrients, if required to introduce to the contaminant plume for complete reductive dechlorination of carbon tetrachloride and its degradation products. Faris and ITRC [28] point out that the first degradation product, chloroform (CF), may become an inhibitor to this process with certain methanogenic mixed cultures. Chloroform has been observed to inhibit its own degradation and acetate consumption at approximately $330 \mu \mathrm{g} / \mathrm{L}$, under perhaps methanogenic conditions; and the inhibition appears to be less under sulfate-reducing conditions even at a concentration of approximately $2 \mathrm{mg} / \mathrm{L}$ [29]. However, in another study, carbon tetrachloride degradation continued even when chloroform concentrations accumulated as high as $10 \mathrm{mg} / \mathrm{L}$ [30]. Accumulated chloroform concentrations higher than $2 \mathrm{mg} / \mathrm{L}$ did not seem to inhibit carbon tetrachloride degradation in pure cultures of a methanogen, a sulfate reducer, and a clostridium species [31]. The CF concentrations, in Figures 4 and 5, are generally less than 330 $\mu \mathrm{g} / \mathrm{L}(2.76 \mu \mathrm{M})$ and no significant inhibition of CT degradation was observed at these concentrations.

With glucose as an electron donor the indigenous microorganisms degraded CT to achieve greater than $94 \%$ removal of inlet $\mathrm{CT}$ and degradation compounds, with a mean residence of less than 4 days, which was less than the time required for more complete transformation of CT. For instance, it took 12 to 24 days for complete biotransformation of CT under several different electron acceptor conditions [32]. Similar removal rates (median CT removal efficiencies of $98-99.9 \%$ ) were reported in a bioaugmentation field demonstration project [33] conducted in Schoolcraft, MI. The CT removal was achieved by subsurface $\mathrm{pH}$ 
adjustments and injecting strain $\mathrm{KC}$, in an aquifer containing $\mathrm{CT}$ and nitrate. Intermittent inoculation, and addition of acetate, alkali and phosphorus were required to maintain strain $\mathrm{KC}$.

After the role of glucose in the degradation of CT was studied and understood well, it was decided to change the supplement in this channel. Cheese whey, a byproduct of cheese manufacturing, which is inexpensive, was chosen as an alternate electron donor. One liter of 0.1 $\%(\mathrm{v} / \mathrm{v})$ cheese whey solution was fed to channel 5 starting on day 903, until day 1136 in intervals of about every 10 days. The outlet CT concentration started to decrease from day 965 , almost 60 days from the beginning of cheese whey addition. From day 994 to the end of the study, the outlet CT concentration remained between 2 to $6 \mu \mathrm{M}$. The outlet CT concentration did not decrease to low levels (below $1 \mu \mathrm{M}$ ) as was the case with glucose, however, $\mathrm{CF}$ concentration was well below $2 \mu \mathrm{M}$. Cheese whey sugars consist primarily of lactose at a concentration of approximately $5 \%$ [34]. In each feeding, $1 \mathrm{~mL}$ of cheese whey was added that contains $5 \%$ of lactose or $50 \mathrm{mg}$, i.e., about $150 \mathrm{mg}$ in a month. This is approximately seven times the theoretical requirement for degradation of CT [24]. Although, CT was not completely degraded with the amount of cheese whey added in this study, cheese whey was demonstrated as a suitable substrate for CT degradation. Further studies are recommended to determine the amount of cheese whey and dosing frequency to optimize removal of $\mathrm{CT}$ and its degradation products.

\section{Channel 6: SOME}

Figure 5 shows the CT degradation pattern in the SOME fed channel. One liter of $0.1 \%$ SOME (v/v) was added once every month starting from day 203 until day 445. Outlet CT decreased to low levels within 40 days after the first dose of SOME addition, unlike the slow response in the glucose amended channel. $\mathrm{CF}$ and $\mathrm{MC}$ were observed but $\mathrm{CF}$ was not detected 
above a concentration of $2.7 \mu \mathrm{M}$. Similar results were observed by Witt et al [37] in a laboratory column study to evaluate the potential for intrinsic bioremediation of CT and related chlorinated methanes with acetate as organic substrate. Transient metabolites (CF and MC) were occasionally observed over the course of the study. However, complete dechlorination of CT was reported in most microcosms at the end of a one-year study [35].

In channel 6, MC concentration increased and decreased regularly (Figure 5). This oscillation may be due to the variation of the mean residence time of the liquid in the channel. During the beginning of a month, the plants were harvested, and therefore, the evapotranspiration rate was minimal. During these days, most of the water flowed out and, therefore, the mean residence time of the compounds was less. However, at the end of the month, when the plants were larger, the evapotranspiration rate was higher and the daily outlet volume was lower. This led to higher mean residence times and consequently, higher degradation of MC. The outlet concentration of CT was below $1 \mu \mathrm{M}$ until day 621 even after feeding was stopped on day 445 . SOME consists of methyl esters of linoleic, oleic, palmitic, linolenic and stearic fatty acids in that order of predominance with mean molecular weight of 292.2 [36]. The amount of SOME fed each month was in excess of what was stoichiometrically required to completely degrade the incoming CT [24].

It was assumed that SOME, being hydrophobic and not very soluble in water, may experience flow retardation due to adsorption to the soil organic matter and therefore, a major portion of the SOME injected may stay at the entrance of the channel. To make the substrate available in the downstream part of the channel, a dose of SOME (100 mL of 1\% SOME (v/v)) was added to well 3 (60 $\mathrm{cm}$ from inlet) on day 445 . After this addition, the total concentration of chlorinated compounds in the outlet decreased and remained lower from day 550 to day 740 , 
except for a couple of samples. After day 750, the substrates were most likely depleted and the concentration of CT started to increase at the outlet. However, it took up to day 825 for the concentration of CT in the outlet to rise above $10 \mu \mathrm{M}$, and the modest concentrations of CF and MC were evidence for continued biodegradation. SOME emulsion was again added on days 837, 957 (injected through well 2), 990 (well 1) and 1020 (well 3). The concentrations of CT and CF decreased due to these supplement additions reaching a low value of $0.5 \mu \mathrm{M}$ and $0.46 \mu \mathrm{M}$ respectively, on day 1036; the total concentration of chlorinated compounds decreased to less than $1 \mu \mathrm{M}$.

Based on the tracer results, the maximum mean residence time at the end of a month is 2.3 days for channel 5 and 3.4 days for channel 6 . Within this duration, the entire incoming CT was degraded during several sampling events. The values of half-life of CT observed in the channels are very low compared to those observed in other studies: Liang and Grbic-Galic [37] reported half-life values in the range 4.6 to 14 days in laboratory experiments with jet fuel, gasoline and natural carbon in soil as substrates. In another study, Boopathy [32] reported biotransformation times of 12 to 24 days for CT under several different electron acceptor conditions.

\section{Relevance to Remediation Goals}

The lowest values of total chlorinated methanes were $0.8 \mu \mathrm{M}$ in channel 5 and $1.0 \mu \mathrm{M}$ in

channel 6. The maximum contaminant levels in drinking water are $0.03 \mu \mathrm{M}$ for $\mathrm{CT}, 0.84 \mu \mathrm{M}$ for $\mathrm{CF}$ and $0.06 \mu \mathrm{M}$ for MC. Out of 83 sampling events in 1136 days, the outlet $\mathrm{CT}$ concentration was below MCL on six occasions in channel 5 and on one occasion in channel 6 . After the addition of supplements channel 5, the outlet CF concentration was below MCL during 16 out of 60 sampling events from day 146 to day 1136 in and MC was below MCL during 46 out of 60 
sampling events. After the addition of SOME, MC was below MCL during 5 out of 58 sampling events from day 226 to day 1106 in channel 6 . The end point of MCL is usually a strict standard and, therefore, based on risk assessment, higher concentration of end point termed alternate cleanup level (ACL) may be permitted and used in field remediation [38]. The desired levels can be achieved by increasing the concentration of supplements, frequency of feeding, and the length of the channel. The reported time required for more complete transformation of $\mathrm{CT}$ was of the order of 12-24 days [32] and half-lives were observed in the range 4.8-14 days [39]; thus, a greater mean residence time beyond that used here (2-5 days) is recommended for achieving cleanup goals.

\section{Well Samples}

The schematic of the channel and the monitoring wells are shown in Figure 1. Figure 6 shows the concentration profile of $\mathrm{CT}$ and the degradation compounds along channel 6 , on day 438; the inlet corresponds to $0 \mathrm{~cm}$ and the outlet is $110 \mathrm{~cm}$. The five intermediate data points correspond to the five wells, with the distance of each well from the inlet as the X-axis. The total chlorinated methanes (Total CMes) decreased from $\sim 12 \mu \mathrm{M}$ to $\sim 7 \mu \mathrm{M}$ (Figure 6) with most of the degradation taking place in the initial portion of the channel, between the inlet and well 1. Although the individual compounds' concentrations changed along the length of the channel, the total CMes remained almost constant around the $6 \mu \mathrm{M}$ level. This indicates that whatever little substrates were available were consumed for the degradation of CT to MC, but degradation of $\mathrm{MC}$ was not taking place. Chloroform was observed, but the concentration was less than $1.5 \mu \mathrm{M}$ and remained at that value throughout the length of the channel. Methylene chloride persisted in the channel and the outlet solution. The uniform concentration of CF, starting from well 1 to the end of the channel, implies that the SOME injected at the inlet resided near the inlet and was not 
available after well 1 . However, there is evidence of modest rate of degradation of CT from well 3 to the outlet, with corresponding increase in MC concentration. The intermediate compound, $\mathrm{CF}$, however, neither accumulated nor disappeared in this zone. It is possible that the CF formed by degradation of CT was converted to MC between the sampling wells.

Analysis of well samples on day 495 revealed that the addition of SOME, to well 3 on day 445, led to considerable decrease of MC in the outlet (Figure 7). Most of the CT was degraded between the inlet $\&$ well 1 , with accumulation of MC until well 3. The SOME added in well 3 had a prominent effect on the degradation of MC, resulting in a decrease of total CMes to below $3 \mu \mathrm{M}$, compared to the $7 \mu \mathrm{M}$ on day 438 when SOME was not available after well 1 . The high concentration of MC at well 3 may be related to the MC in the SOME phase. The CMes concentrations remained low in well samples collected on days 590 and 614 indicating continued supply of carbon and electron donors from earlier SOME injection [24]. The wells were analysed on additional days: $382,395,409,460,555,644,686,712,775,804,831,864,928$ and 984 ; the results for these days are available in Santharam [40].

\section{Soil Samples}

The mass of aqueous phase and the moisture content fraction, and the dry weight of soil in soil samples collected on days 96 and 151 were estimated [24]. Samples were collected at a distance of $30 \mathrm{~cm}$ from inlet on day 96 , and at a distance of $57 \mathrm{~cm}$ from inlet on day 151 . On day 96, the concentration of $\mathrm{CT}$ for samples collected at depth $34-42 \mathrm{~cm}$ (from the soil surface) was $1.4 \mu \mathrm{M}$ in channel 4 and $0.47 \mu \mathrm{M}$ in channel 6; $\mathrm{CT}$ was not detected in other samples. CT was not detected in channel 5 at the depths that were investigated. The mass of aqueous phase increased with depth as expected, since the water diffuses through the vadose zone and evaporates through the soil surface, thus creating a gradient in moisture content. 
On day 151, CT was not detected in the soil samples from channels 4 and 5. In channel 6, the concentrations were $0 \mu \mathrm{M}$ in the depth $0-8 \mathrm{~cm}, 0.07 \mu \mathrm{M}$ in the depth $12-20 \mathrm{~cm}, 0.09 \mu \mathrm{M}$ the depth $22-30 \mathrm{~cm}$ and $0.17 \mu \mathrm{M}$ in the depth $34-42 \mathrm{~cm}$. The concentration of CT increases with depth but was very low compared to the inlet/flow regime concentration of $13 \mu \mathrm{M}$. As shown in Table 6 , the fractions of organic matter content $\left(f_{o c}\right)$ in the soil samples collected on day 151 were less than $1 \%$.

In the soil samples collected on day 230, at a distance of $65 \mathrm{~cm}$ from the inlet, the concentration of CT increased from $0 \mu \mathrm{M}$ at $4 \mathrm{~cm}$ below the soil surface to $0.35 \mu \mathrm{M}$ at $37 \mathrm{~cm}$ below the soil surface in channel 4 ; and from 0 to $0.7 \mu \mathrm{M}$ in channel 6 . On day 354 , no CT or intermediate products were detected in channels 5 and 6, since CT was degraded (see Figures 4 and 5).

\section{Surface Flux Analysis}

In all samples collected from the inverted container on the soil surface, the concentrations of CT and the degradation products were not detected. There may not have been appreciable concentrations of CT and degradation products volatilizing to the soil surface. Any compounds transported upwards by volatilization were biodegraded due to the effective environment for biodegradation provided by the root zone.

\section{Conclusions}

Channeling occurs in the bottom zone of the channels leading to lower mean residence times than that predicted for uniform flow. In the tracer study conducted in the three channels immediately after harvesting plants, the peak bromide concentration in the outlet occurred between 1.1 to 1.5 days corresponding to an outlet liquid volume of $1.1 \mathrm{~L}$ to $1.4 \mathrm{~L}$. 
Supplements such as glucose, corn starch, cheese whey and SOME stimulated the indigenous microbes and helped in the degradation of carbon tetrachloride (CT). However, the pattern and rate of degradation of CT were different for different supplements. As a result, the degradation compound ratios in the glucose/corn starch/cheese whey amended channel were not similar to those in the SOME amended channels. The fraction removals of total chlorinated methanes in the outlet liquid were $94 \%$ in glucose fed channel and $92 \%$ in SOME fed channel.In both channels, the degradation continued many days after stopping the feeding of supplements. The soil matrix and the microorganisms were able to store the supplements/degradation products of supplements and provide a long-term source of carbon and hydrogen. This fact is very important in the design of remediation systems in field sites and it can be used to determine the frequency for supplement addition. Glucose was found to be a better supplement than cheese whey for CT degradation; however, further study is necessary to determine if the concentration and frequency of cheese whey addition can be modified to improve CT degradation.

The outlet MC in SOME fed channel was higher and varied with the mean residence time, unlike the glucose fed channel, where the concentration of MC was uniform irrespective of the time of month. Most of the degradation process took place in the initial portion of the SOME fed channel where SOME was present, since SOME likely stayed near the inlet of the channel; due to high sorption and low solubility, the flow of SOME was retarded. SOME was present as a non-aqueous phase liquid (NAPL) and did not flow freely like an aqueous solution.

In the soil sample analysis, CT was not detected in the vadose zone near the soil surface, but it was found in the saturated zone at detectable concentrations, in channels 4 and 6 . No CT or degradation products were detected in the gas phase above the soil surface. Any compounds 
transported upwards by volatilization were biodegraded due to the effective environment for biodegradation provided by the root zone.

This study demonstrated that the supplements glucose and SOME are effective substrates that can be added to CT contaminated groundwater to promote degradation of CT. Glucose was found to be a better supplement than SOME and cheese whey for CT degradation; however,

further study is necessary to determine if mixtures of sugars, SOME, and cheese whey may improve the degradation process.

\section{Acknowledgments}

This work is contribution 10-180-J of the Kansas Agricultural Experiment Station. We are grateful for financial support provided by the Kansas Department of Health and Environment and the Kansas Agricultural Experiment Station. We would like to thank Dr. Stacy Hutchinson, Biological and Agricultural Engineering, Kansas State University for use of laboratory facilities for analyzing chlorinated methanes and bromide.

Please send questions or comments to Dr. S. Santharam, corresponding author. 


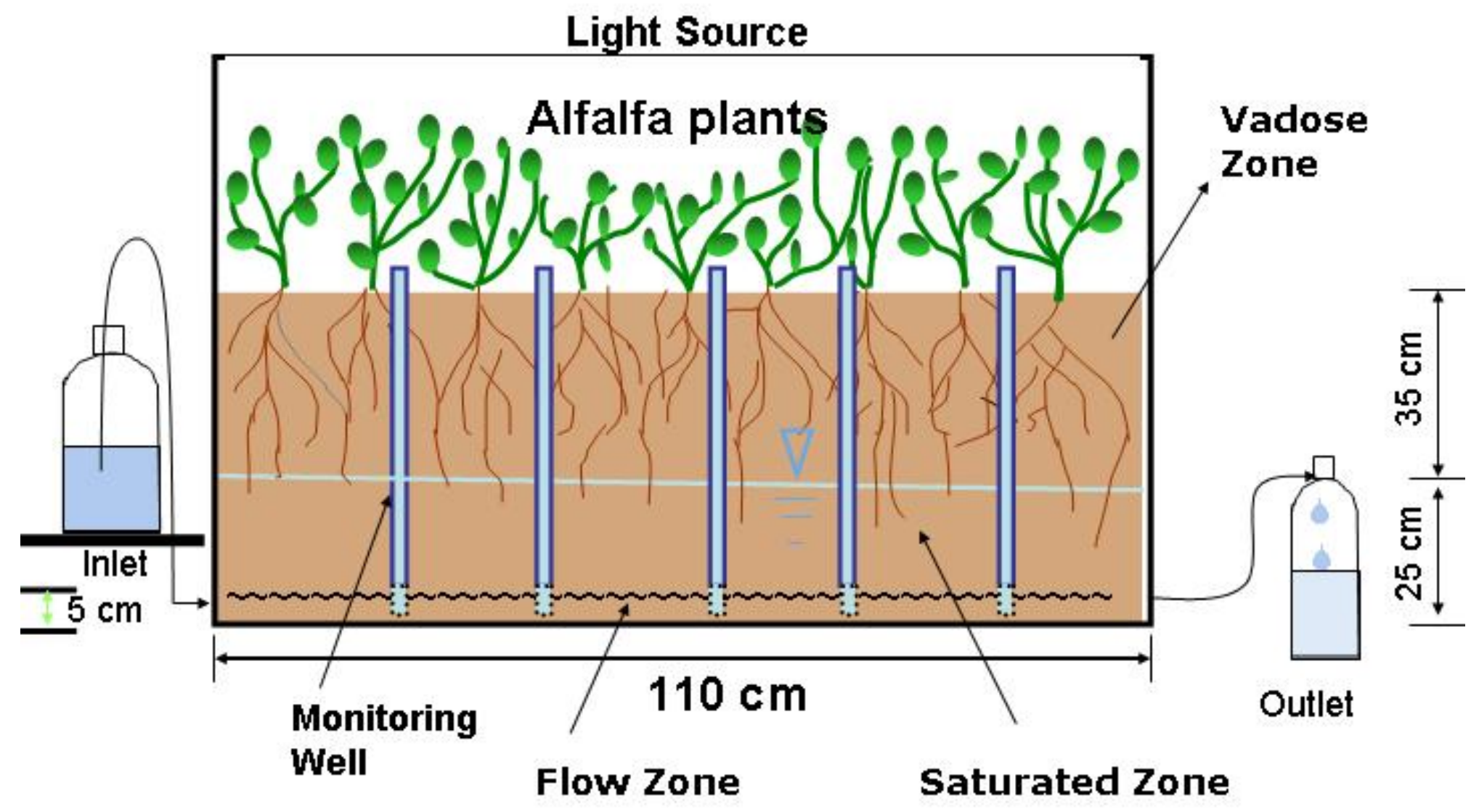

Figure 1. Schematic and cross section of a channel in the six-channel system. 


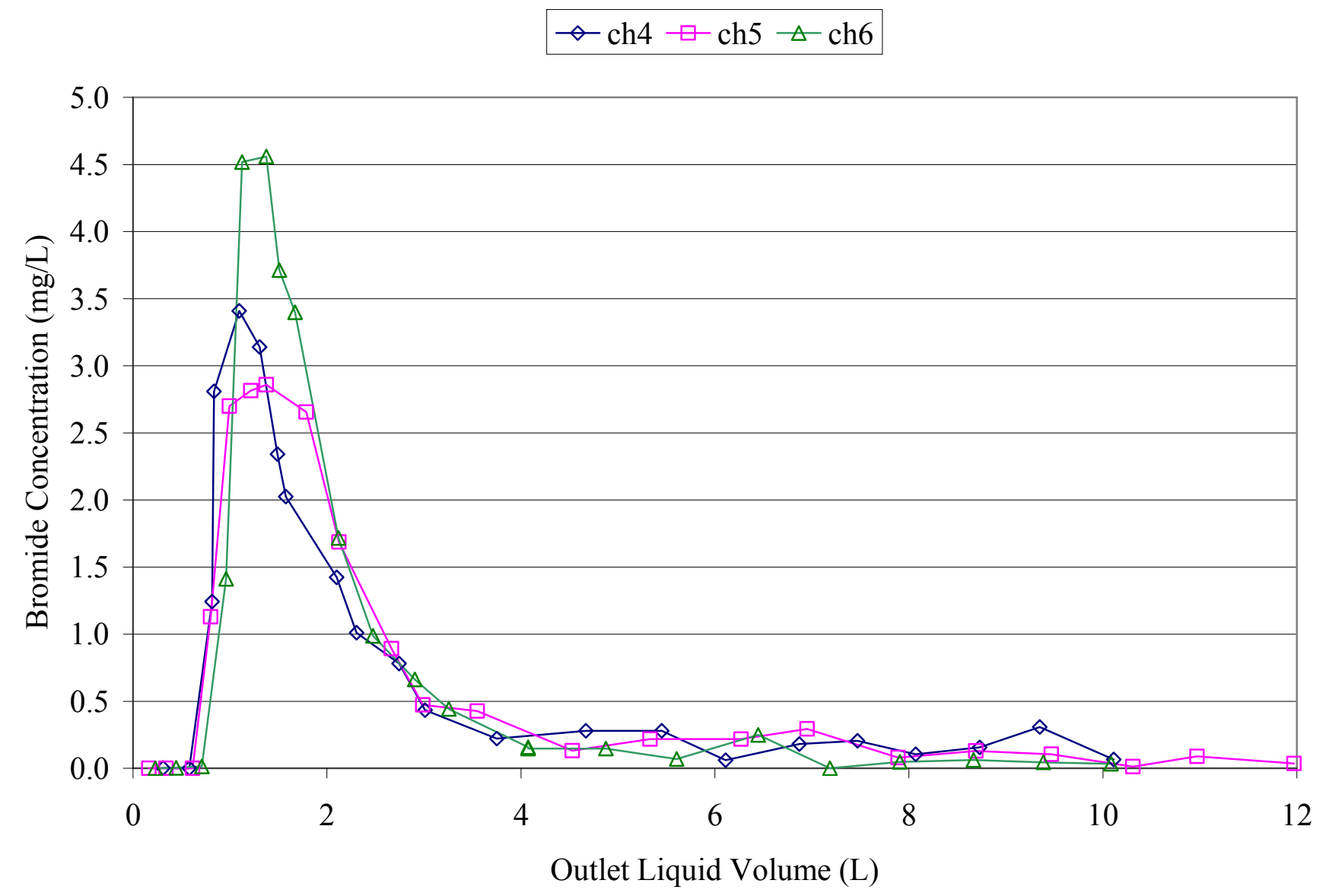

Figure 2. Concentration of bromide in the outlet liquid vs cumulative outlet liquid volume for channels 4,5 and 6 . Inlet bromide concentration $=100 \mathrm{mg} / \mathrm{L}$. 


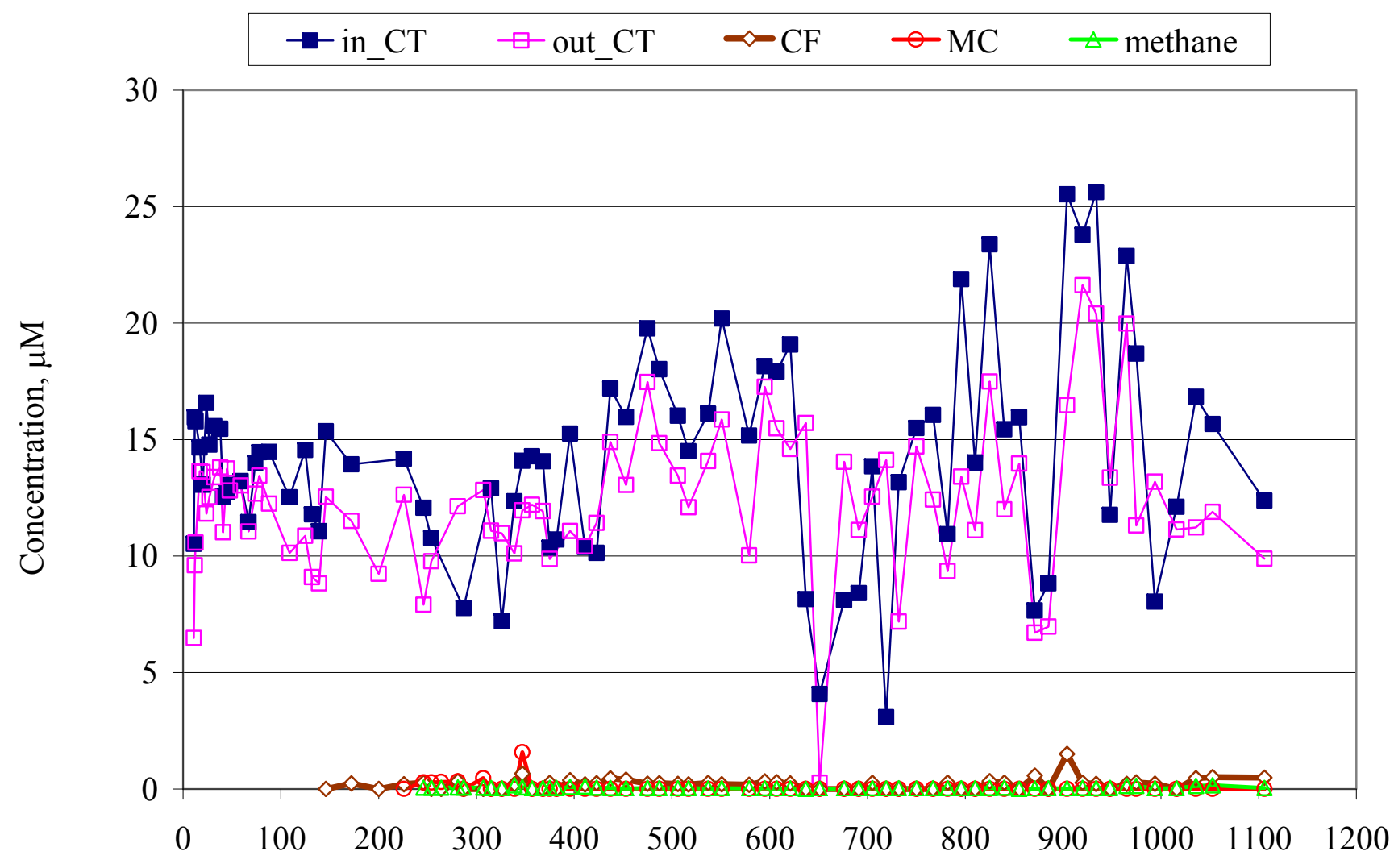

Treatment time (days)

Figure 3. Inlet CT and outlet CT, CF, MC and methane concentrations for channel 4 (control). Water samples taken on indicated days after beginning (March 12, 2004) exposure. 


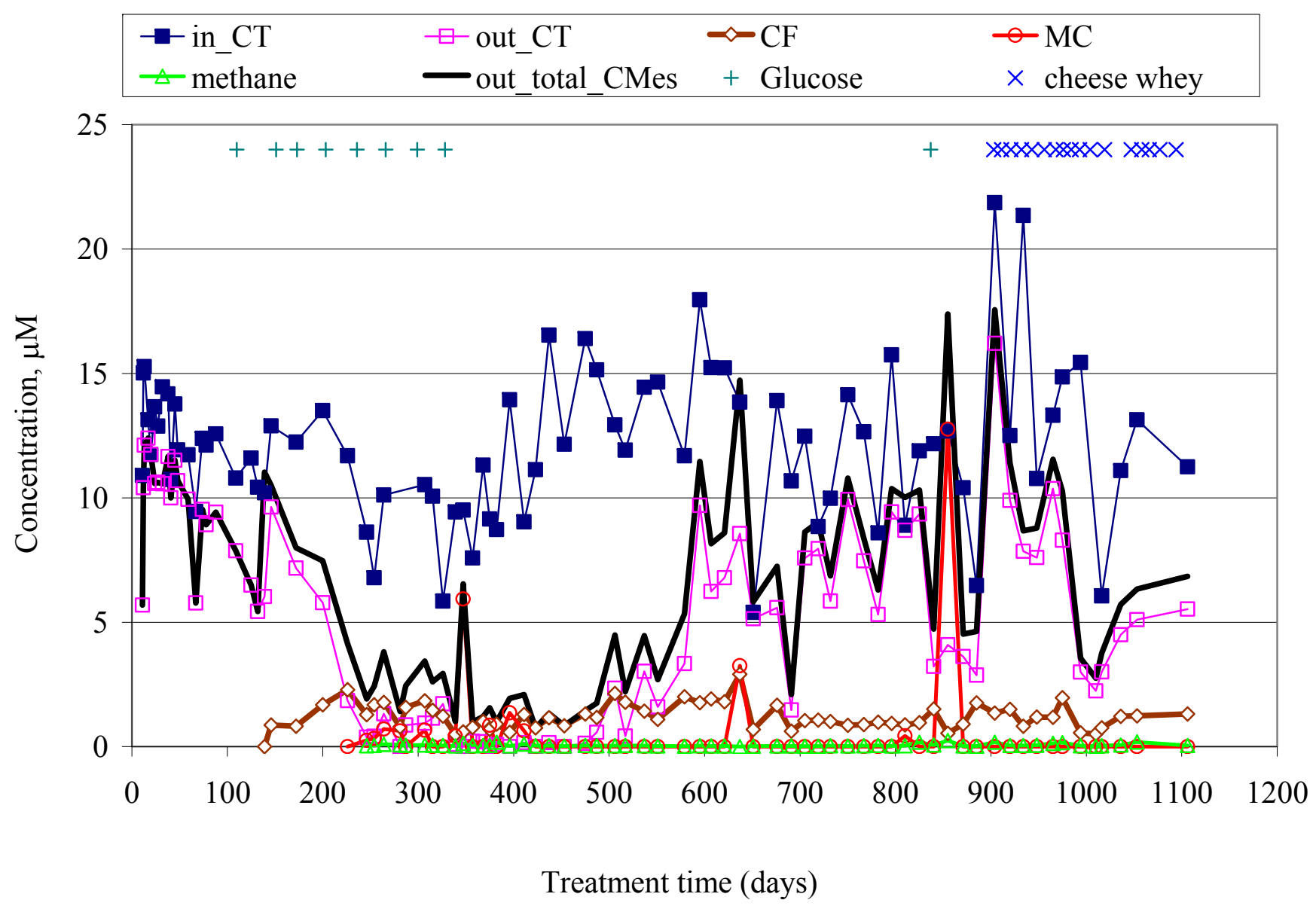

Figure 4. Inlet $\mathrm{CT}$ and outlet $\mathrm{CT}, \mathrm{CF}, \mathrm{MC}$ and methane concentrations for channel 5 . Water samples taken on indicated days after beginning (March 12, 2004) exposure. Glucose solution was added on days 110, 151, 173, 203, 236 and 837; corn starch on days 266, 299 and 328. Cheese whey was added on days 903, 911, 921, 932, 943, 956, 968, 976, 984, 993, 1004, 1019, 1047, 1058, 1077, 1094 and 1111 . 


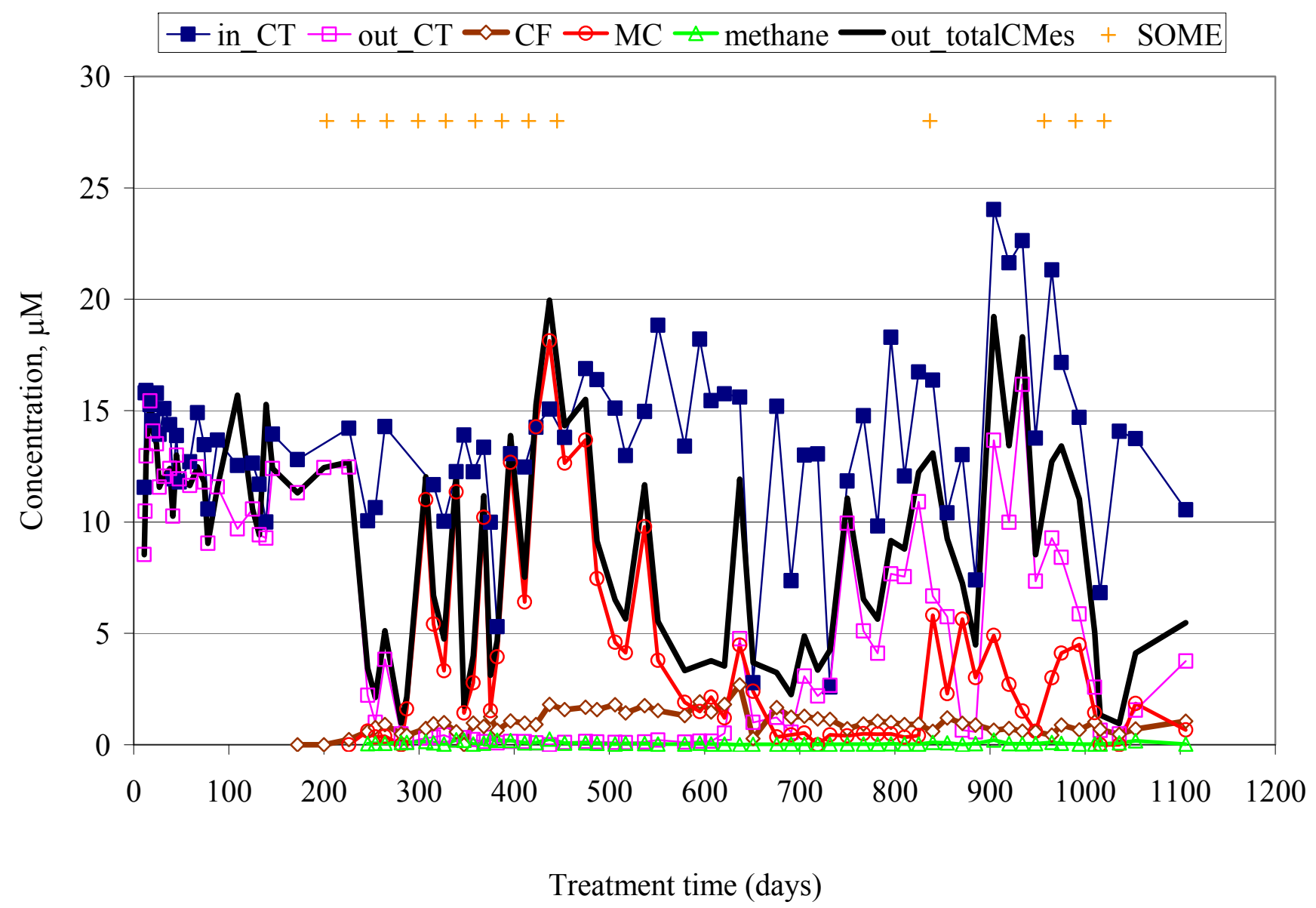

Figure 5. Inlet $\mathrm{CT}$ and outlet $\mathrm{CT}, \mathrm{CF}, \mathrm{MC}$ and methane concentrations for channel 6 . Water samples taken on indicated days after beginning (3/12/2004) exposure. Soy Oil Methyl Esters (SOME) added on days 203, 236, 266, 299, 328, 359, 387, 415, 445 (well 3), 837, 957 (well 2), 990 (well 1) and 1020 (well 3). 


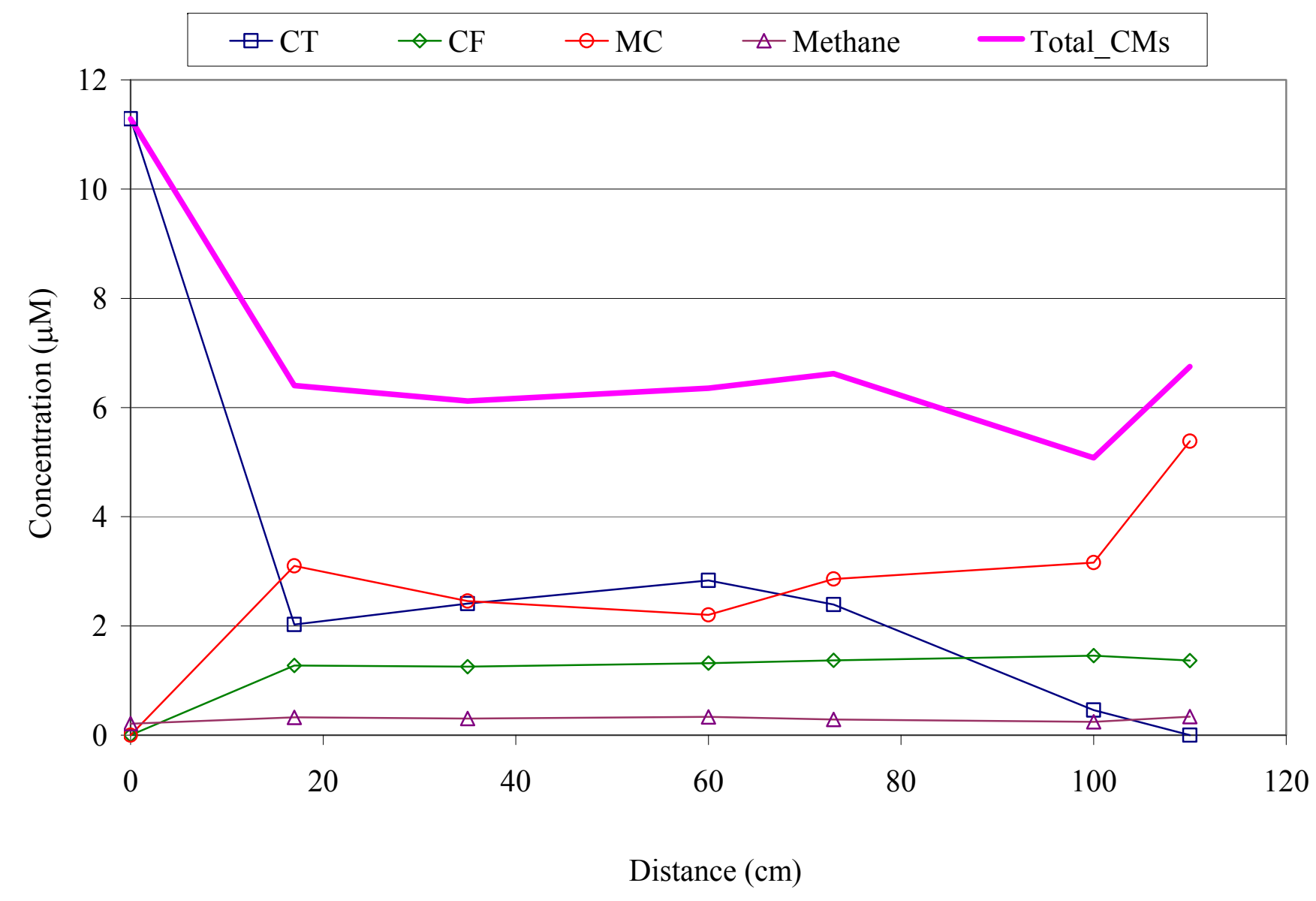

Figure 6. Variation of CT and degradation compounds with distance along channel 6 on day 438, 5/24/05. Soy Oil Methyl Esters (SOME) added on days 203, 236, 266, 299, 328, 359, 387 and 415. 


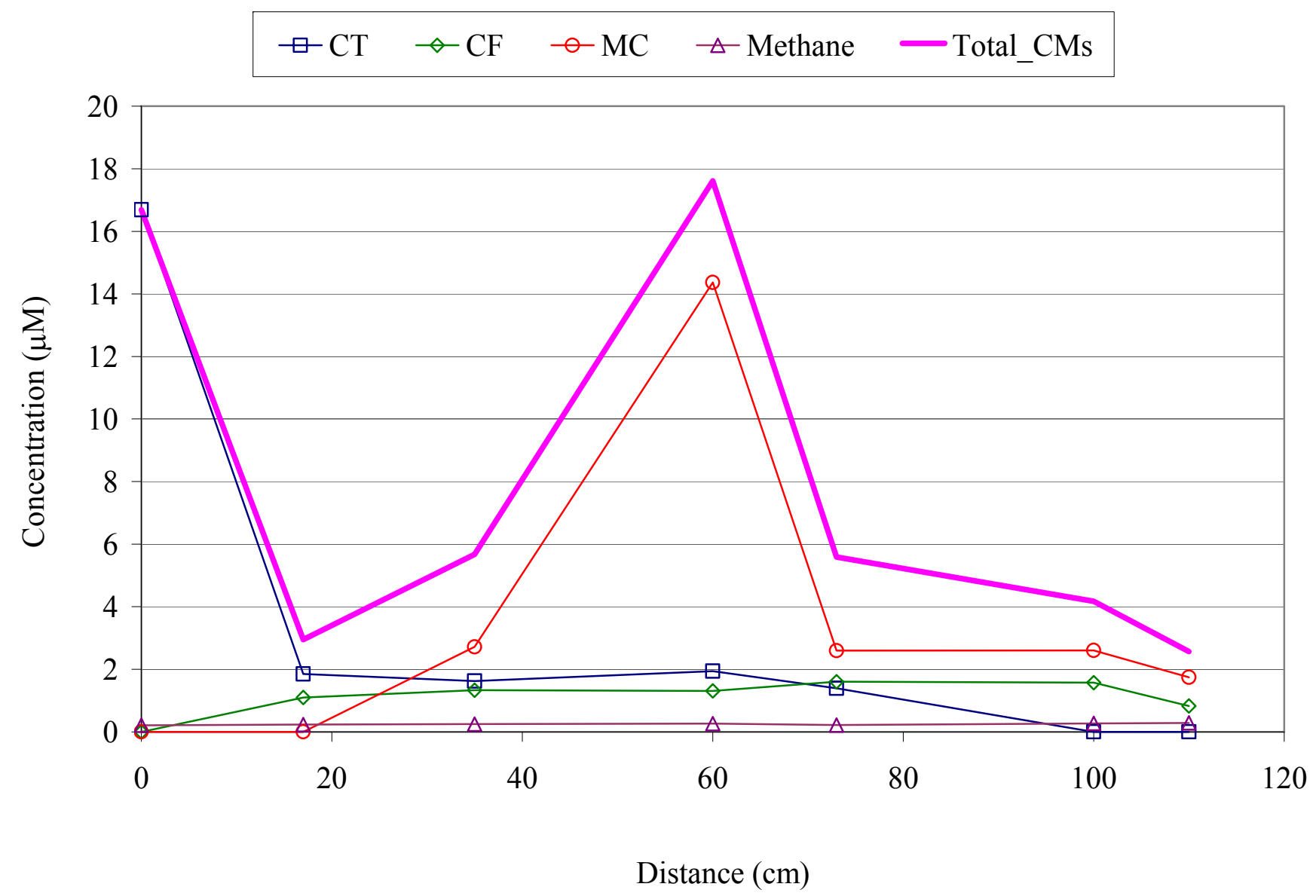

Figure 7. Variation of CT and degradation compounds with distance along channel 6 on day 495, 7/21/05. Soy Oil Methyl Esters (SOME) added on days 203, 236, 266, 299, 328, 359, 387, 415 and 445 (well 3). 
Table 1. Supplements feeding history for channels 5 and 6.

\begin{tabular}{|l|c|c|c|}
\hline \multicolumn{1}{|c|}{ Date } & Day & Channel 5 & Channel 6 \\
\hline 2004 & & & \\
\hline June 30 & 110 & G & \\
\hline August 10 & 151 & G & \\
\hline September 1 & 173 & G & \\
\hline October 1 & 203 & G & S \\
\hline November 3 & 236 & G & S \\
\hline December 3 & 266 & CS* & S \\
\hline 2005 & & & \\
\hline January 5 & 299 & CS* & S \\
\hline February 3 & 328 & CS* & S \\
\hline March 6 & 359 & & S \\
\hline April 3 & 387 & & S \\
\hline May 1 & 415 & & S \\
\hline May 31 & 445 & & S (well 3)\# \\
\hline 2006 & 9321 & CW & \\
\hline June 27 & 937 & G & S \\
\hline September 1 & 903 & CW & \\
\hline September 9 & 911 & CW & \\
\hline September 19 & 921 & CW & \\
\hline September 30 & 932 & CW & \\
\hline October 11 & 943 & & \\
\hline October 24 & 956 & & \\
\hline October 25 & 957 & & \\
\hline November 5 & 968 & & \\
\hline
\end{tabular}




\begin{tabular}{|l|c|c|l|}
\hline \multicolumn{1}{|c|}{ Date } & Day & Channel 5 & Channel 6 \\
\hline November 13 & 976 & $\mathrm{CW}$ & \\
\hline November 21 & 984 & $\mathrm{CW}$ & \\
\hline November 27 & 990 & & S (well 1) \\
\hline November 30 & 993 & $\mathrm{CW}$ & \\
\hline December 17 & 1004 & $\mathrm{CW}$ & \\
\hline December 26 & 1019 & $\mathrm{CW}$ & \\
\hline December 27 & 1020 & & S (well 3) \\
\hline 2007 & & & \\
\hline January 23 & 1047 & $\mathrm{CW}$ & \\
\hline February 3 & 1058 & $\mathrm{CW}$ & \\
\hline February 11 & 1066 & $\mathrm{CW}$ & \\
\hline February 22 & 1077 & $\mathrm{CW}$ & \\
\hline March 11 & 1094 & $\mathrm{CW}$ & \\
\hline March 28 & 1111 & $\mathrm{CW}$ & \\
\hline April 12 & 1126 & $\mathrm{CW}$ & \\
\hline April 22 & 1136 & $\mathrm{CW}$ & \\
\hline
\end{tabular}

Key: G - Glucose; CS - Corn Starch; CW - Cheese Whey; S - SOME or Soy Oil Methyl Esters.

* From December 3, 2004 to February 3, 2005, Corn Starch was added instead of glucose, inadvertently.

\# In Channel 6, $100 \mathrm{~mL}$ of $1 \%$ SOME was injected into the well number indicated in the paranthesis, through nylon tubing; the solution was fed near the bottom of the channel. 
Table 2. Peak concentration of bromide in outlet and mean residence time for channels 4,5 and 6 . Inlet bromide concentration $=100$ $\mathrm{mg} / \mathrm{L}$.

\begin{tabular}{|c|c|c|c|c|}
\hline Channel & $\begin{array}{l}\text { Volume of } \\
\text { outlet liquid } \\
(\mathrm{L})^{*}\end{array}$ & $\begin{array}{l}\text { Peak bromide } \\
\text { concentration } \\
\text { time (days)* }\end{array}$ & $\begin{array}{l}\text { Bromide peak } \\
\text { concentration in } \\
\text { outlet liquid }(\mathrm{mg} / \mathrm{L})\end{array}$ & $\begin{array}{l}\text { Mean } \\
\text { residence } \\
\text { time (days) }\end{array}$ \\
\hline 4 & 1.095 & 1.125 & 3.41 & 3.6 \\
\hline 5 & 1.375 & 1.42 & 2.86 & 3.4 \\
\hline 6 & 1.375 & 1.25 & 4.56 & 2.8 \\
\hline
\end{tabular}

*Values are the liquid volume and residence time associated with the peak concentration.

\# Mean residence time was estimated from the residence time distribution (RTD) model. 
Table 3. Bromide Mass balance for tracer study in channels 4, 5 and 6, for the 14 day period.

\begin{tabular}{|c|l|l|l|l|l|l|}
\hline Channel & $\begin{array}{l}\text { Cumulative } \\
\text { volume of outlet } \\
\text { water (L) }\end{array}$ & $\begin{array}{l}\text { Cumulative water } \\
\text { uptake by plants } \\
\text { (L) }\end{array}$ & $\begin{array}{l}\text { Bromide in outlet } \\
\text { liquid (m) }\end{array}$ & $\begin{array}{l}\text { Bromide trapped in } \\
\text { soil by upflow* (mg) }\end{array}$ & Total bromide \\
accounted (mg) \\
recovery (\%)
\end{tabular}

*Estimated based on the assumption that the bromide concentration in the upflow due to evapotranspiration is the same as that in the outlet liquid for a particular day.

${ }^{\#}$ The mass of bromide added at the inlet was $10.05 \mathrm{mg}$. 
Table 4. Bromide recovery vs solution recovery in channels 4, 5 and 6, for the 14 day period, from June 4, 2004 to June 18, 2004.

\begin{tabular}{|c|c|c|c|c|}
\hline Channel & $\begin{array}{l}\text { Volume of outlet liquid } \\
\text { over total liquid fed }(\mathrm{L} / \mathrm{L})\end{array}$ & Solution & Bromide in outlet liquid & Bromide \\
& & & & \\
& $10.11 / 14.84$ & 68 & 5.26 & 52 \\
\hline 4 & $11.97 / 14.25$ & 84 & 5.42 & 54 \\
\hline 5 & $10.09 / 13.36$ & 76 & 5.50 & 55 \\
\hline
\end{tabular}


Table 5. Effect of evapotranspiration on the residence time of compounds in channels 4, 5 and 6; Estimated from data in June 2004.

\begin{tabular}{|c|l|l|l|l|}
\hline Channel & $\begin{array}{l}\text { Variation in the daily exit } \\
\text { liquid volume (L/day) for } \\
1 \text { month period }\end{array}$ & $\begin{array}{l}\text { Volume of exit liquid } \\
\text { for peak concentration } \\
\text { of tracer (L) }\end{array}$ & $\begin{array}{l}\text { Peak } \\
\text { time } \\
\text { (days) }\end{array}$ & $\begin{array}{l}\text { Estimated variation in the time for the volume of } \\
\text { liquid (corresponding to peak bromide concentration) } \\
\text { to exit at the start and the end of a month (days)* }\end{array}$ \\
\hline 4 & $0.9-0.6$ & 1.095 & 1.125 & $1.4-1.8$ \\
\hline 5 & $0.9-0.6$ & 1.375 & 1.42 & $1.5-2.3$ \\
\hline 6 & $0.9-0.4$ & 1.375 & 1.25 & $1.7-3.4$ \\
\hline
\end{tabular}

*This value is obtained by dividing the volume of exit liquid corresponding to peak concentration by the volume of liquid collected at the outlet each day, at the beginning and the end of June 2004. For example, for channel 4, the time taken for collecting $1.095 \mathrm{~L}$ of liquid at the outlet in the beginning of June 2004 is 1.095/0.8 = 1.4 days and similarly, the time taken for collecting $1.095 \mathrm{~L}$ of liquid at the outlet at the end of June 2004 is $1.095 / 0.6=1.8$ days. 
Table 6. Fraction of organic matter content (as \%) in CT channel soil samples (day 151).

\begin{tabular}{|c|c|c|c|c|}
\hline Sample & Depth (cm) & Channel 4 & Channel 5 & Channel 6 \\
\hline 1 & $0-8$ & 0.55 & 0.44 & 0.34 \\
\hline 2 & $12-20$ & 0.25 & 0.63 & 0.48 \\
\hline 3 & $24-32$ & 0.45 & 0.66 & 0.37 \\
\hline 4 & $34-42$ & 0.47 & 0.75 & 0.27 \\
\hline
\end{tabular}




\section{References}

1. ATSDR. (2007). Agency for Toxic Substances and Disease Registry. Toxicological profile for carbon tetrachloride. Atlanta, GA: U.S. Department of Health and Human Services, Public Health Service. http://www.atsdr.cdc.gov/toxprofiles/tp30-c2.pdf.

2. Hashsham, S. A., Scholze, R., \& Freedman, D. L. (1995). Cobalamin-enhanced anaerobic biotransformation of carbon tetrachloride, Environmental Science and Technology, 29, 28562863.

3. Flathman, P.E., Jerger, D.E., \& Woodhall, P.M. (1992). Remediation of dichloromethane (DCM) - contaminated ground water, Environmental Progress 11, 202-209.

4. Rogers, J.A., Tedaldi, D.J. \& Kavanaugh, M.C. (1993). A screening protocol for bioremediation of contaminated soil, Environmental Progress 12, 146-156.

5. Kriegman-King, M. R., \& Reinhard, M. (1994). Transformation of carbon tetrachloride in the presence of sulfide, biotite, and vermiculite, Environmental Science and Technology, 28, 692-700.

6. Mokrauer, J.E. \& Kosson, D.S. (1989). Electrophysical adsorption of single carbon halogenated solvents onto soil, Environmental Progress 8, 1-5.

7. Tekrony, M.C., \& Ahlert, R.C. (2001). Adsorption of chlorinated hydrocarbon vapors onto soil in the presence of water. Journal of Hazardous Materials, 84, 2-3, 135-146, ISSN 0304-3894, 10.1016/S0304-3894(01)00186-8.

8. Semprini, L., \& McCarty, P. L. (1992). Comparison between model simulations and field results for in-situ biorestoration of chlorinated aliphatics, 2, Cometabolic transformations, Ground Water, 30, 1, 37- 44 . 
9. Hull, L. C., \& Sondrup, A. J. (2003). Degradation of chlorinated solvents in the vadose zone at a radioactive waste subsurface disposal area. Idaho National Engineering and Environmental Laboratory Idaho Falls, ID. http://www.mathesontrigas.com/msds/MAT04310.pdf

10. McQuillan, D.M., Faris, B.H., \& Swanson, B.H. (1998). Intrinsic cometabolism of carbon tetrachloride with gasoline: regulatory site closure, In International Conference on Remediation of Chlorinated and Recalcitrant Compdounds, Natural Attenuation. Wickramanayake, G.B., and Hinchee, R.E., Eds. Battelle Press, Columbus, OH, pp 263-268.

11. Witt, M. E., Dybas, M. J., Wiggert, D. C., \& Criddle, C. S. (1999). Use of bioaugmentation for continuous removal of carbon tetrachloride in model aquifer columns, Environmental Engineering Science, 16, 6, 475-485.

12. Gregory, K.B., Mason, M.G., Picken, H.D., Weathers, L.J., \& Parkin, G.F. (2000). Bioaugmentation of $\mathrm{Fe}(0)$ for the remediation of chlorinated aliphatic hydrocarbons, Environmental Engineering Science, 17, 169-181.

13. Semprini, L., Hopkins, G.D., McCarty, P.L., \& Roberts, P.V. (1992). In-situ transformation of carbon tetrachloride and other halogenated compounds resulting from biostimulation under anoxic conditions, Environmental Science \& Technology, 26, 2454-2461.

14. Witt, M.E., Dybas, M.J., Worden, R.M., \& Criddle, C.S. (1999). Motility enhanced bioremediation of carbon tetrachloride-contaminated aquifer sediments, Environmental Science \& Technology, 33, 2958-2964.

15. Dybas M. J., Barcelona, M., Bezborodnikov, S., Davies, S., Forney, L., Heuer, H., Kawka, O., Mayotte, T., Sepulveda-Torres, L., Smalla, K., Sneathen, M., Tiedje, J., 
Voice, T., Wiggert, D. C., Witt, M. E., Criddle, C. S. (1998). Pilot-scale evaluation of bioaugmentation for in-situ remediation of a carbon tetrachloride-contaminated aquifer, Environmental Science \& Technology, 32, 3598-3611.

16. Phanikumar, M.S., Hyndman, D.W., Wiggert, D.C., Dybas, M.J., Witt, M.E., \& Criddle, C.S. (2002). Simulation of microbial transport and carbon tetrachloride biodegradation in intermittently-fed aquifer columns, Water Resources Research, 38, 4-1-4-13.

17. Guerrero-Barajas, C., \& Field, J.A. (2006). Enhanced anaerobic biotransformation of carbon tetrachloride with precursors of vitamin B12 biosynthesis, Biodegradation, 17, 4, 317-329.

18. Shan. H., Kurtz, H. D., Jr \& Freedman, D. L. (2010). Evaluation of strategies for anaerobic bioremediation of high concentrations of halomethanes, Water Research, 44, 1317-1328.

19. Fu, Q.S., Boonchayaanant, B, Tang, W, Trost, B.M., \& Criddle C. S. (2009). Simple menaquinones reduce carbon tetrachloride and iron (III), Biodegradation, 20, 109-116.

20. Alvarez, L. H., Jimenez-Bermudez, L., Hernandez-Montoya, V., Cervantes, F.J. (2012). Enhanced Dechlorination of Carbon Tetrachloride by Immobilized Fulvic Acids on Alumina Particles. Water, Air, \& Soil Pollution, 223, 4, 1911-1920.

21. Cervantes, F. J., Martínez, C. M., Gonzalez-Estrella, J., Márquez, A., \& Arriaga, S. (2013). Kinetics during the redox biotransformation of pollutants mediated by immobilized and soluble humic acids, Applied Microbiology and Biotechnology, 97, 6, 2671-2679.

22. Zhang, Q. (1999). Phytoremediation of methyl tert-butyl ether. (MTBE) in groundwaterexperimental and modeling. studies, PhD Dissertation, Kansas State University, Manhattan, KS. 
23. Santharam, S. (2008). Laboratory and field investigation of chlorinated solvents remediation in soil and groundwater. A Ph.D. Dissertation, Department of Chemical Engineering, Kansas State University, Manhattan, KS. http://hdl.handle.net/2097/910.

24. Santharam, S. (2010). Bioremediation of Chlorinated Solvents in Aquifers-Laboratory and Field Studies, VDM Publishers, Saarbrucken, Germany.

25. Levenspiel, O. (1999). Chemical reaction engineering, Wiley, New York, NY.

26. Whitmer, S., Baker, L., \& Wass, R. (2000). Loss of Bromide in a Wetland Tracer Experiment, Journal of Environmental Quality, 29, 2043-2045. 10.2134/jeq2000.00472425002900060043x.

27. Brandi-Dohrn, F.M., Leibundgut, C., Dick, R.P., \& Selker, J.S. (1995). Collecting tracers in the vadose zone Tracer Technologies/or Hydrological Systems, Proceedings of a Boulder Symposium, IAHS Publ.no. 229, 1995. 173.

28. Faris, B., \& ITRC-In Situ Bioremediation Team. (2002). A systematic approach to in-situ bioremediation of carbon tetrachloride in groundwater, Proceedings of the 2002 Conference on Application of Waste Remediation Technologies to Agricultural Contamination of Water Resources.

29. Gupta, M., Gupta, A., Suidan, M., \& Sayles, G. (1996). Biotransformation Rates of Chloroform Under Anaerobic Conditions? Methanogenesis, Water Research, 30, 1377.

30. Freedman, D., Lasecki, M., Hashsham, S., \& Scholze, R. (1995). Accelerated biotransformation of carbon tetrachloride and chloroform by sulfate-reducing enrichment cultures, In Bioremediation of Chlorinated Solvents; Hinchee, R. E., Leeson, A., Semprini, L., Eds.; Batelle Press: Columbus, OH, 123-137. 
31. Egli, C., Tschan, T., Scholtz, R., Cook, A., \& Leisinger, T. (1988). Transformation of Tetrachloromethane to Dichloromethane and Carbon Dioxide by Acetobacterium woodii, Applied Environmental Microbiology, 54, 2819.

32. Boopathy, R. (2002). Anaerobic Biotransformation of Carbon Tetrachloride under Various Electron Acceptor Conditions, Bioresource Technology, 84, 69-73.

33. Stroo, H. F., Leeson, A., \& Ward, C. H. (2013). Bioaugmentation for Groundwater Remediation,SERDP and ESTCP Remediation Technology Monograph Series, Springer.

34. Ghaly, A. E., Kamal, M., \& Avery, A. (2003). Influence of temperature rise on kinetic parameters during batch propagation of Kluyveromyces fragilis in cheese whey under ambient conditions, World Journal of Microbiology \& Biotechnology, 19, 7, 741-749.

35. Witt, M. E., West, R. J., Davis, J. W., \& Klecka, G. M. (2001). Results of laboratory microcosm studies to investigate intrinsic biodegradation of carbon tetrachloride in a fractured basalt aquifer, Editor(s): Leeson, Andrea. International In-Situ and On-Site Bioremediation Symposium, 6th, San Diego, CA, United States, June 4-7, 2001, 2, 89-96. Publisher: Battelle Press, Columbus, Ohio.

36. Marion. S. (2007). Biodiesel: An alternative to petroleum diesel, Penn State University http://www.personal.psu.edu/users/s/c/scm207/Production.htm, accessed 4/25/2007.

37. Liang, L. N., \& Grbic-Galic, D. (1993). Biotransformation of Chlorinated Aliphatic Solvents in the Presence of Aromatic Compounds under Methanogenic Conditions, Environmental Toxicology and Chemistry, 12, 1377-1393.

38. Anderson, P., Olsen, R., \& Kaufman, J.R. (2004). Liquid assets, Civil Engineering, 5157, September 2004.

39. Truex, M. J., Murray, C.J., Cole, C.R., Cameron, R.J., Johnson, M.D., Skeen, R.S., \& Johnson. C.D. (2001). Assessment of Carbon Tetrachloride Groundwater Transport in 
Support of the Hanford Carbon Tetra-chloride Innovative Technology Demonstration Program, Pacific Northwest National Laboratory, US Department of Energy.

40. Santharam, S. (2008). A Supplement to the Ph.D. Dissertation: Laboratory and field investigation of chlorinated solvents remediation in soil and groundwater. Department of Chemical Engineering, Kansas State University, Manhattan, KS.

http://hdl.handle.net/2097/910. 